\title{
EFICIÊNCIA DE CORDÕES DE PEDRA EM CONTORNO NA RETENÇÃO DE SEDIMENTOS E MELHORAMENTO DE PROPRIEDADES DE UM SOLO LITÓLICO(1)
}

\author{
J.R.C. SILVA ${ }^{(2)} \&$ F. J.da SILVA ${ }^{(3)}$
}

\begin{abstract}
RESUMO
E $m$ face de suas características de moderada a alta erodibilidade e pequena profundidade efetiva, os solos litólicos requerem eficientes práticas conservacionistas no sentido de protegerem sua estreita camada arável, que é ameaçada por altas taxas de erosão em regiões semi-áridas do Estado do Ceará. Conhecem-se bem as conseqüências da erosão nesses solos, porém são escassas as pesquisas sobre os efeitos, a longo prazo, das práticas conservacionistas sobre a intensidade de perdas de solo, bem como sobre o melhoramento de suas propriedades. Treze anos após a construção de cordões de pedra em contorno, a massa de sedimentos retida e as mudanças que esta prática de controle da erosão induziu nas características quími cas, físicas e topográficas de um solo litólico foram avaliadas. O experimento foi executado em Quixadá (CE ), de março a julho de 1994. Sob declive de $0,03 \mathrm{~mm}^{-1}$, essa prática conservacionista reteve uma média de $60 \mathrm{t} \mathrm{ha}^{-1}$ ano-1 $^{-1}$ de sedimentos em camadas de até $0,30 \mathrm{~m}$ de espessura ao longo das barrei ras de pedra. As deposições, provocadas por esses obstáculos às enxurradas, formaram, progressivamente, patamares pelo nivelamento natural da superfície original do terreno. Essa prática conservacionista induziu expressivos melhoramentos na qualidade do solo relacionados à elevação dos seguintes parâmetros: profundidade efetiva, porosidade, água disponível, matéria orgânica, nitrogênio, soma de bases, saturação de bases e capaci dade de troca de cátions; por outro lado, verificou-se um decréscimo de alumínio nas camadas de sedimentos retidos pelos cordões de pedra, ao longo dos treze anos de controle da erosão.
\end{abstract}

Termos de indexação: sedi mentos, controle da erosão, patamares, qualidade do solo.

\section{SUMMARY: EFFECTIVENESS OF STONE BARRIER CONTOURS ON SEDIMENT RETENTION AND IMPROVEMENT OF CHEMICAL AND PHYSICAL PROPERTIES IN A LITHOLIC SOIL}

Litholic soi Is arecharacterized by moderateto high erodibility and low depth. Dueto these attributes, litholic soils require effective conservation practices protecting their thin top soil layer from thehigh erosi on rates in thesemiarid regions of theState of Ceará, Brazil. While the

\footnotetext{
(1) Parte da Tese de Mestrado do segundo autor apresentada ao Departamento de Ciência do Solo da Universidade Federal do Ceará. Financiada pelo CNPq. Recebido para publicação em junho de 1996 e aprovado em abril de 1997.

(2) Professor Titular do Departamento de Ciência do Solo da Universidade Federal do Ceará. Caixa Postal 12.168, CEP 60455-760 Fortaleza (CE). Bolsista do CNPq.

(3) Engenheiro-Agrônomo. Mestre em Solos e Nutrição de Plantas. Pró-Reitoria de Extensão. Universidade Federal do Ceará. CEP 60455-760 Fortaleza (CE).
} 
consequences of erosion on these soils are well known, thelong term effects of this conservation practiceon therateof soil l osses and improvement of their properties have been scarcely studied. Mass of retained sediment and changes in chemical, physi cal and topographical characteristics of a litholic soil were determined thi rteen years after the construction of stonebarrier contours. The experiment was conducted in Quixadá, State of Ceará, Brazil, from March to J uly, 1994.

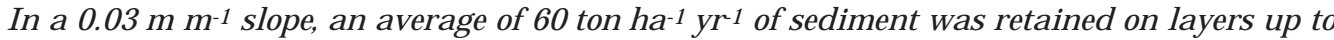
0.30 m deep al ong thestonebarriers. Deposition induced by thoseobstacles to runoff progressively formed bench terraces through natural levelling of theoriginal terrain surface This conservation practice induced significant improvements in soil quality, increasing effective depth, porosity, available water, organic matter, nitrogen, sum of bases, base saturation and cation-exchange capacity and decreasing al umi num content.

Index terms: sediment, erosi on control, bench terraces, soil quality.

\section{INTRODUÇÃO}

Em face de suas características de moderada a alta erodibilidade, pequena profundidade efetiva, presença de pedregosidade, al tas taxas de desmatamento e uso predatório em agricultura de subsistência, os solos litólicos requerem um criterioso manejo e maior atenção ao aspecto conservacionista (Margolis et al., 1985), do que a usual mente dispensada no E stado do Ceará (Silva, 1994). Estudos preliminares desenvolvidos por Silva \& Paiva (1985) anunciavam que os cordões de pedra em contorno constituiriam promissora técnica antierosiva, a partir de observações de redução do assoreamento em reservatórios deágua, alertando para os benefícios que os sedimentos retidos por essa prática poderiam proporcionar, em curto prazo, na mel horia das propriedades dos sol os litól icos. Os cordões de pedra em contorno segmentam o comprimento dos declives, fazem diminuir o volume ea velocidade das enxurradas, forçam a deposição de sedimentos nas áreas onde são construídos e formam patamares naturais. Em conseqüência, provocam aumento na profundidade efetiva do sol o e diminuem os desgastes provocados pela exportação de sedimentos, nutrientes e matéria orgânica, melhorando a condição de infiltração e o armazenamento deágua para as plantas (Rosso, 1982; Shaxson et al., 1989).

Entretanto, ainda não foram determinados os efeitos dos cor dões de pedra em estimativas das taxas de retenção de sedimentos e na caracterização das possíveis mudanças que promovem, aolongo do tempo, nos solos sob sua proteção. Considerando que o conhecimento desses efeitos em campo poderá definir, com maior clareza, as vantagens dessa técnica conservacionista, pela sua influência no aumento da produtividade do solo, este trabal ho foi desenvolvido com os seguintes objetivos:

a) Estimar a massa de sedimentos retidos por meio do controle da erosão proporcionado pel os cordões de pedra em contorno, após treze anos de sua construção, em área de pastagem sob solo litólico;

b) Avaliar a influência dessa prática na modificação da topografia original do terreno e na profundidade efetiva do solo; c) Determinar, após esse longo prazo, as mudanças nas características físicas equímicas do sol o nas áreas de deposi ção de sedimentos, sob influência de cordões de pedra em contorno, quando comparadas àquelas onde predominam processos de remoção e transporte de sedimentos.

\section{MATERIAL E MÉTODOS}

As determinações foram desenvol vidas na Fazenda Lavoura Seca da Universidade Federal do Ceará, situada no Município de Quixadá (CE ), em sol o litólico eutrófico $A$ fraco textura média fase pedregosa caatinga hi poxerófila rel evo suave ondulado substrato gnaisse. A área em estudo situa-se numa encosta ao norte de uma barragem vertedora, cuja água supre parte da demanda da fazenda. Essa área estava, há 13 anos, sob uso de pastagem natural, com sinais de superpastejo por bovinos e ovinos em alguns locais. Silva \& Paiva (1985), estudando a área experimental, observaram que sob declividades de 0,03 a 0,15 m m1 , os longos comprimentos das vertentes (de até mais de $150 \mathrm{~m}$ ) constituíam fatores agravantes do processo erosivo no solo daquela área. Com a finalidade de diminuir a intensidade de deposição de sedimentos na barragem dessa área, foram construídos nove cordões de pedra em contorno, total izando $2.180 \mathrm{~m}$ de comprimento. Nesse sentido, pedras com diâmetro médio de $0,15 \mathrm{~m}$ foram empilhadas a uma altura aproximada de 0,40 m e uma largura similar ao longo de todo o comprimento de cada cordão em nível, cujo espaçamento vertical variou de 0,50 a $3,50 \mathrm{~m}$. O primeiro cor dão de pedra ficou distando $15 \mathrm{~m}$ da linha d'água do reservatório e o último, no divisor de água da vertente, $200 \mathrm{~m}$ dessa linha, entre os quais foram locados os seter restantes, a espaçamentos de 17 a 24 m, em função da declividade.

Treze anos após a construção dos cordões de pedra, uma área de $625 \mathrm{~m}^{2}$ foi preparada com implementos manuais, efetuando-se o plantio de milho e caupi para anál ise comparativa da produtividade do sol o sob essas condições e sob as condições normais de remoção e deposição de sedimentos, conforme descrito no trabalho de Silva \& Silva (1997). No topo da encosta 
(declividade de $0,03 \mathrm{~m} \mathrm{~m}^{-1}$ ), foram realizadas nove amostragens à profundidade de 0 a $15 \mathrm{~cm}$, ao longo de $25 \mathrm{~m}$ de um dos cordões de pedra em contorno, formando amostras compostas, com três repetições dos seguintes tratamentos:

1. Deposição (D): amostragens efetuadas imediatamente a montante e tangenciando o cordão de pedra, onde se evidenciavam a retenção e a deposição de sedimentos por essa prática, em decor rência da diminuição da veloci dade e da energia cinética das enxurradas;

2. Remoção (R): amostragens a $19 \mathrm{~m}$ do cor dão de pedra, onde era visível o efeito da desagregação e transporte do solo.

A massa de terra retida, em t ha-1, foi estimada por meio do cál culo do volume da secção transversal da camada de acumulação de sedimentos, estendida ao longo de 100 metros de comprimento do cordão de pedra, após trezeanos de sua construção. Essa secção transversal (Figura 1) tinha a forma de um triângulo retângulo cuja altura (h) era a espessura da camada de sedimentos em contato direto com o cordão de pedra, medida por diferença entre a altura original da barreira de pedras ea al tura atingi da pela camada de acumulação desses materiais. A base desse triângulo (b) era formada pela superfície aplainada do patamar desenvolvido naturalmente e sua hipotenusa (a) caracterizava-se pela linha formada pela superfície original do terreno em declive de $0,03 \mathrm{~m} \mathrm{~m}^{-1}$, determinada antes da construção dos cordões.

A área desse triângulo $\left(\mathrm{m}^{2}\right)$, multiplicada por $100 \mathrm{~m}$, forneceu o volume de terra acumulada $\left(\mathrm{m}^{3}\right)$, cujo val or multiplicado pela média da densidade global dessa camada (determinada em três repetições), fornece a massa de terra retida. O somatório das massas de sedimentos acumulados ao longo dos cordões existentes na área de 1 ha, cujo espaçamento foi calculado em função da declividade da área em estudo, permitiu a estimativa do total de terra retida nessa superfície. Dividindo-se essetotal por treze anos, obteve-se a média anual de retenção de sedimentos pelos cordões de pedra em contorno em t ha-1 ano-1.
As propriedades físicas e químicas do solo nas áreas de deposição e remoção de sedimentos foram determinadas em uma amostragem composta de nove volumes de terra de $500 \mathrm{~cm}^{3}$, col etados à profundidade de 0-15 cm, em três diferentes locais de cada tratamento. Seguiu-se o Manual de Métodos de Análise de Solo do Serviço Nacional de Levantamento e Conservação de Solos da EMBRAPA (1979) para a determinação da granulometria, densidade global, densidade de partícula, porosidade, água disponível, matéria orgânica, C, N, P, K, Ca, Mg, H eAl, em cada uma das três repetições de cada tratamento. As médias dos val or es de cada uma dessas propriedades nos dois tratamentos foram comparadas pelo teste de Tukey, ao nível de $5 \%$.

\section{RESULTADOS E DISCUSSÃO}

\section{Controle da erosão, formação natural de patamares e estimativa da deposição de sedimentos}

Para a declividade de 0,03 m m-1 na área experimental, observaram-se a deposição ea retenção de uma massa de sedimentos que, em contato com o cordão de pedra, atingia uma altura de $30 \mathrm{~cm}$. Em função do gradiente original da superfície do terreno, esse material originário da desagregação etransporte do solo na área de remoção foi, ao longo de 13 anos, sedimentando e suavizando o declive, até nivelar-se com o solo a cerca de 10 m (Figura 1). O cálculo da secção transversal triangular (1,5 m²), formada pela base de $10 \mathrm{~m}$ de comprimento e altura de 0,3 m, correspondente à deposição dos sedimentos ao longo de $100 \mathrm{~m}$ lineares do cordão de pedra, permitiu o cál cul o do vol ume deterra retido igual a $150 \mathrm{~m}^{3}$. Para uma densidade de $1,3 \mathrm{~kg} \mathrm{dm}^{-3}$, esse volume equivale a uma massa de $195 \mathrm{t}$. Na declividade de 0,03 $\mathrm{m} \mathrm{m}^{-1}$ da área delimitada para o experimento, os cordões de pedra estão espaçados de 24 m, ocorrendo, portanto, em número de quatro por hectare. A soma das massas retidas pelas barreiras de pedras em 1 ha nessas condições corresponde, portanto, a 780 t no período de 13 anos, equivalendo a uma média de 60 t ha-1 ano-1 de solo mantido nessa área confinada, de pequena

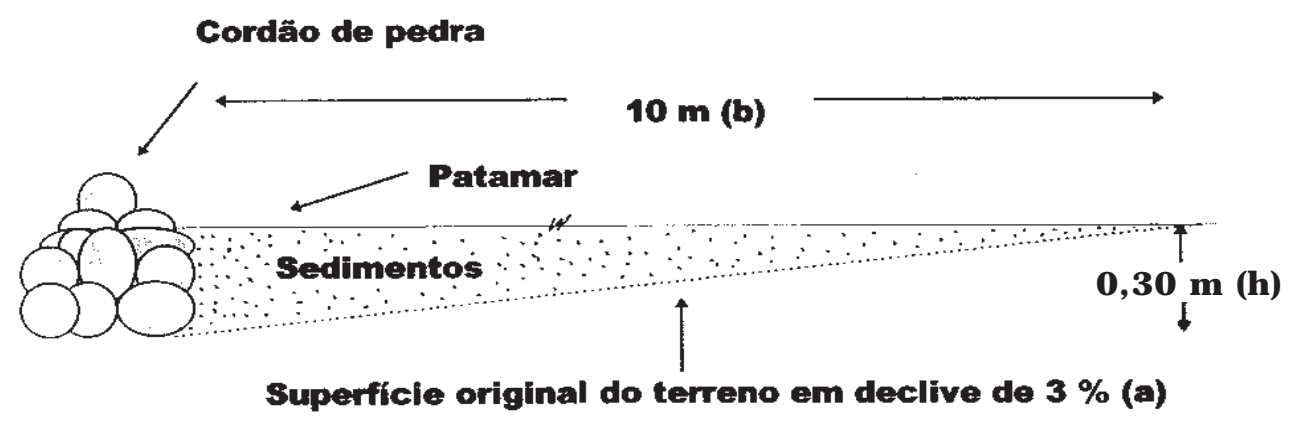

Figura 1. Esquema da deposição do solo desagregado, transportado e retido sob forma de sedimentos pelo cordão de pedra em contorno (b), com a suavização do declive (a), formando um patamar natural (h). 
profundidade efetiva. Sob declividades maiores, como a de $0,15 \mathrm{~m} \mathrm{~m}^{-1}$, que ocorrem em áreas contíguas, a retenção e a deposição de terra superavam muitas vezes aquela massa de sedimentos, posto que, em alguns locais, os cordões já se apresentavam soterrados pelo acúmulo de solo transportado e depositado. Evidencia-se, portanto, a importância dessa prática conservacionista tanto no aumento da profundidade efetiva do solo litól ico em estudo, quanto na gradativa modificação das condições microtopográficas, pelo nivelamento do terreno em função da deposição de sedimentos. Diminuindo os efeitos da principal limitação dos solos litólicos, caracterizada pela pequena profundidade efetiva, os cordões de pedra em contorno efetivamente contribuíram para a melhoria da produtividade por meio de maior volume de terra disponível ao ar, à água, à retenção denutrientes eao melhor desenvol vimento do sistema radicular das plantas.

Considerando quea massa de $60 \mathrm{t} \mathrm{ha}^{-1} \mathrm{ano}^{-1}$ retida pelos cordões de pedra em contorno corresponde a cerca de doze vezes a tolerância de perdas de solo estabelecida para solos rasos como os litólicos, os resultados aqui expostos concordam com as observações de Hudson (1981), Silva (1994) e Corrêa (1994), no que concerne à gravidade do problema da erosão nas regiões tropicais. Nessas, a forte agressividade das chuvas e, particularmente, o inadequado uso e manejo do solo têm conduzido muitas áreas anteriormente produtivas ao limiar da desertificação (Dregne, 1978). Ficam também evidenciadas as conclusões de Rosso (1982), Silva \& Paiva (1985) eShaxson et al. (1989) sobre controle da erosão, aumento da vida útil dos reservatórios de água, melhoria de áreas para cultivo, suavização do declive e formação natural de patamares, em função da deposição de sedimentos ao longo dos cordões de pedra. Entretanto, a associação dos cordões de pedra em contorno com práticas de cobertura morta do solo e, ou, a redução dos espaçamentos entre os cordões seriam alternativas para um controle ainda mais efetivo da erosão pois os espaçamentos adotados não evitaram a remoção de terra na parte superior das áreas entre cordões.

\section{Propriedades físicas}

Os resultados da análise granulométrica revelam mudanças nos teores de areia, silte e argila com diferenças significativas nos dois tratamentos (Quadro 1).

Enquanto o teor de areia no tratamento $\mathbf{R}$ (remoção) foi superior ao do $\mathbf{D}$ (deposição), neste, os teores desilte eargila apresentaram aumentos de 53,1 e $113,3 \%$, respectivamente, em relação ao primeiro.

A melhoria nas propriedades de retenção e armazenamento de água do solo, influenciada pelo aumento do teor de argila, pode ser avaliada pela água disponível e pela porosidade, que aumentaram 63,3 e $8,8 \%$, respectivamente, nas camadas de deposição em relação às de remoção (Quadrol). Esse acréscimo na água disponível foi conseqüência direta do aumento da ordem de 111,5 e 173,7\% na água retida a -0,03 e $-1,5 \mathrm{MPa}$ respectivamente, determinado no tratamento $\mathbf{D}$, por comparação com os valores determinados no R. O menor conteúdo de água disponível, no tratamento $\mathbf{R}$, está coerente com a menor porosidade encontrada nesse tratamento, onde a má estrutura não só di ficulta a expansão das raízes, mas também reduz a aeração (Shaxson et al., 1989). A maior porosidade no tratamento $\mathbf{D}$, por sua vez, foi influenciada pela redução de 10,3\% no valor da densidade gl obal determinada nesse tratamento, em relação à $\mathbf{R}$.

\section{Carbono, nitrogênio e matéria orgânica}

De forma semelhante ao que ocorreu com as características físicas, o efeito benéfico da prática conservacionista em estudo materializou-se por meio do aumento de $\mathrm{C}, \mathrm{N}$ e matéria orgânica nas camadas de deposição dos sedimentos (Quadros 1 e 2). Nessas camadas, os teores de nitrogênio e matéria orgânica foram, respectivamente, 1,7 e 3 vezes maiores do que aqueles determinados na área de remoção. Esse notável aumento da matéria orgânica constituiu um dos efeitos mais significativos do ponto de vista de mel horia da produtividade do solo, proporcionada pelo cordão de pedra, pois atingiu um patamar quesupera em cerca de $180 \%$ os teores desse constituinte do sol o em regiões semi-áridas do Ceará (Ministério da

Quadro 1. Características físicas da camada arável $(0-20 \mathrm{~cm})$ do solo litólico determinadas nas áreas de remoção e deposição de sedimentos. Médias de três repetições

\begin{tabular}{lccc}
\hline Características & Remoção & Deposição & DMS(1) \\
\hline Areia grossa $(2-0,2 \mathrm{~mm}), \mathrm{g} \mathrm{kg}^{-1}$ & $400 \mathrm{a}$ & $323 \mathrm{~b}$ & 65 \\
Areia fina $(0,2-0,05 \mathrm{~mm}), \mathrm{g} \mathrm{kg}^{-1}$ & $403 a$ & $327 \mathrm{a}$ & 86 \\
Silte $(0,05-0,002 \mathrm{~mm}), \mathrm{g} \mathrm{kg}^{-1}$ & $113 a$ & $173 \mathrm{~b}$ & 41 \\
Argila $(<0,002 \mathrm{~mm}), \mathrm{g} \mathrm{kg}^{-1}$ & $84 \mathrm{a}$ & $177 \mathrm{~b}$ & 93 \\
Densidade global, $\mathrm{kg} \mathrm{dm}^{-3}$ & $1,45 \mathrm{a}$ & $1,30 \mathrm{a}$ & 0,18 \\
Densidade de partícula, kg dm & $2,35 \mathrm{a}$ & $2,56 \mathrm{a}$ & 0,12 \\
Porosidade calculada, m m-3 & $0,45 \mathrm{a}$ & $0,49 \mathrm{a}$ & 0,05 \\
Água disponível, $\mathrm{kg} \mathrm{kg}^{-1}$ & $0,05 \mathrm{a}$ & $0,08 \mathrm{a}$ & 0,04 \\
Matéria orgânica, $\mathrm{g} \mathrm{kg}^{-1}$ & $10,0 \mathrm{a}$ & $30,0 \mathrm{a}$ & 27,0 \\
\hline
\end{tabular}

(1) DMS: Diferença mínima significativa $(0,05)$. Médias seguidas da mesma letra nas linhas não diferem, estatisticamente, pelo teste de Tukey ao nível de $5 \%$. 
Agricultura, 1973). Além disso, ao lado do aumento do teor de argila no tratamento D, o aumento da matéria orgânica está coerente com o incremento da capacidade de troca de cátions detectada no presente estudo, em concordância com trabalho desenvolvido por da Silva et al. (1994). Esse acréscimo assume maior importância ao se verificar que, ao contrário de climas mais frios, onde ocorre maior acúmulo de matéria orgânica, em clima quente e seco, como o do presente estudo, as taxas de oxi dação e as perdas desse constituinte do solo são bastante aceleradas. A melhoria da qualidade do solo, influenciada pela prática conservacionista em estudo, concorda, portanto, com resultados obtidos por Dedecek (1987) e Sparovek et al. (1991, 1993), ao demonstrarem a importância da matéria orgânica não somente na produtividade das culturas, mas na própria recuperação da capacidade produtiva de solos erodidos. Os resultados aqui obtidos reforçam também as conclusões de Hudson (1994), com referência à alta prioridade que deve ser dada às práticas conservacionistas que reduzem a erosão e mantêm os níveis de matéria orgânica no solo. As concl usões deste autor, com referência ao pronunciado efeito da matéria orgânica na capacidade de água disponível do solo, adquirem maior importância ao se considerar a necessidade vital de conservar a água no solo em regiões onde as chuvas são escassas, como no local do presente estudo.

O aumento da matéria orgânica no tratamento D também está coerente com os aumentos da porosi dade e da retenção e disponi bilidade deágua determinados nas camadas de sedimentos depositados ao longo dos cordões de pedra na área de deposição. Além disso, no tratamento D, a disponibilidade de $\mathrm{N}$ também foi maior, pois nenhuma das amostras nesse tratamento apresentou uma relação C/N superior a 30, quando, geral mente, a imobilização excede a mineralização do nitrogênio (Foth, 1978).

\section{Propriedades químicas}

Além do material retido durante treze anos de ocupação da área com pastagem, o cultivo, após esse período, e realizado antes das amostragens, proporcionou maior desagregação etransporte de solo, cujos sedimentos continuaram sendo retidos ao longo do cordão de pedra em contorno, enriquecendo, significativamente, a área onde foram depositados. $\mathrm{O}$ contraste entre o empobrecimento da área onde ocorreu remoção e o enriquecimento e aumento da fertilidade da área onde houve a deposição pode ser avaliado no quadro 2.

Na área de deposição, além de o solo apresentar maior potencial de produtividade, em função da maior disponibilidade de água, do maior teor de matéria orgânica, da maior profundidade efetiva e da maior porosidade, foram encontrados, ainda, benefícios adicionais, como os incrementos de 123,8 e 237,1\% para a capacidade de troca e soma de bases respectivamente.

Individualmente, conforme quadro 2, o cál cio, o magnésio e o potássio foram, respectivamente, 4,5, 1,7 e 1,3 vezes maiores na camada de deposição. Resultados semel hantes também foram determi nados por Resck et al . (1980) em sol o podzól ico, ao detectarem que, na enxurrada, as maiores perdas de nutrientes seguiam a mesma or dem decrescente acima referida. Essa escala de magnitude, naquele trabalho, correspondia, por sua vez, à ordem semelhante à da composição química original do solo, tal como ocorreu no presente estudo, ou seja, $\mathrm{Ca}>\mathrm{Mg}>\mathrm{K}$.

O efeito benéfico do cordão de pedra também se fez presente na reação do solo, em função do al to teor de cálcio retido e da diminuição de 56,5\% no teor de alumínio na área de deposição (Quadro 2), com reflexos positivos na melhoria da qualidade do sol o e no aumento de seu potencial produtivo (Dedecek, 1987).

Por sua vez, conforme quadro 2, o fósforo apresentou-se com baixo teor no tratamento $\mathbf{R}$, refletindo diminuição do potencial de produtividade da área erodida, enquanto, nos sedimentos retidos, o conteúdo desse macronutriente foi 2,3 vezes maior.

O comportamento do fósforo em relação à presença do alumínio mostrou-se idêntico ao observado por Resck et al. (1980): valores mais altos de Al na área

Quadro 2. Características químicas de amostras do solo litólico $(0-15 \mathrm{~cm})$ determinadas nas áreas de remoção e deposição de sedimentos. Médias de três repetições

\begin{tabular}{|c|c|c|c|}
\hline Características & Remoção & Deposição & DMS $^{(1)}$ \\
\hline Carbono, $\mathrm{g} \mathrm{kg}^{-1}$ & $5,8 a$ & $17,6 a$ & 15,9 \\
\hline Nitrogênio, $\mathrm{g} \mathrm{kg}^{-1}$ & $0,4 a$ & $0,6 a$ & 0,5 \\
\hline Capacidade de troca de cátions, $\mathrm{mmol}_{\mathrm{c}} \mathrm{kg}^{-1}$ & $63,2 \mathrm{a}$ & $141,0 \mathrm{~b}$ & 68,0 \\
\hline Soma de bases, mmolc $\mathrm{kg}^{-1}$ & $35,2 a$ & $117,7 \mathrm{~b}$ & 59,4 \\
\hline Cálcio, mmolc $\mathrm{kg}^{-1}$ & $20,3 a$ & $88,7 \mathrm{~b}$ & 51,6 \\
\hline Magnésio, mmol $\mathrm{kg}^{-1}$ & $14,0 \mathrm{a}$ & $24,0 a$ & 12,8 \\
\hline Potássio, mmolc kg-1 & $3,2 a$ & 4,0a & 1,9 \\
\hline Alumínio, mmolc kg-1 & $2,3 a$ & $1,0 a$ & 2,9 \\
\hline Fósforo, $\mathrm{mg} \mathrm{dm}^{-3}$ & $5,3 a$ & $12,0 \mathrm{a}$ & 11,5 \\
\hline
\end{tabular}

(1) DMS: Diferença mínima significativa $(0,05)$. Médias seguidas da mesma letra nas linhas não diferem, estatisticamente, pelo teste de Tukey ao nível de 5\%. 
de remoção $\left(2,3 \mathrm{mmol}_{\mathrm{c}} \mathrm{kg}^{-1}\right)$ corresponderam, proporcionalmente, a valores mais baixos de $P$ $\left(5,3 \mathrm{mg} \mathrm{dm}^{-3}\right)$, enquanto nos sedimentos o teor de Al baixou $\left(1,0 \mathrm{mmol}_{\mathrm{c}} \mathrm{kg}^{-1}\right)$ e o $\mathrm{P}$ aumentou significativamente $\left(12,0 \mathrm{mg} \mathrm{dm}^{-3}\right)$. Essa relação inversamente proporcional entre os teores desses elementos constitui mais uma confirmação do benefício dos cordões de pedra no potencial produtivo do solo, contribuindo, inclusive, para a diminuição de custos com corretivos e fertilizantes (Sparovek et al., 1991).

Evidenciada no presente estudo, a melhoria da qualidade da camada arável do solo em função da técnica conservacionista adotada está em consonância com preocupações de Daniels et al. (1987), conferindo uma ênfase que deveser dada às pesquisas que visam superar os efeitos negativos que a erosão provoca na produtividade do solo e no rendimento das culturas, corroborada por Sparovek et al. (1993).

\section{CONCLUSÕES}

1. A eficiência dos cordões de pedra em contorno como prática conservacionista foi claramente evidenciada por meio da retenção de uma média de 60 t ha-1 $^{-1}$ ano-1 $^{-1}$ de sedimentos.

2. A profundidade efetiva do solo foi aumentada nas áreas de deposição em $30 \mathrm{~cm}$, nas quais, no decorrer do período de treze anos, houve progressiva formação natural de patamares.

3. Em função da massa de sedimentos retida pelo cordão de pedra em contorno na área de deposição, uma sensível melhoria, em todas as propriedades físicas e químicas, é notada, em relação à área de remoção, com aumentos em: profundidade efetiva, matéria orgânica, teor de argila, água disponível, teores de $\mathrm{N}, \mathrm{Ca}, \mathrm{Mg}, \mathrm{K}$ e $\mathrm{P}$, acompanhados de uma diminuição nos teores de Al.

\section{LITERATURA CITADA}

CORRÊA, A.A.M. O Brasil no rumo do inabitável. Boletim Informativo da Sociedade Brasileira de Ciência do Solo, Campinas, 19:38-43, 1994.

DANIELS, R.B.; GILLIAN, J.W.; CASSEL, D.K. \& NELSON, L.A. Quantifying the effects of past soil erosion on present soil productivity. J. Soil Wat. Cons., Ankeny, 42:183-187, 1987.

DEDECEK, R.A. E feitos das perdas e deposição de camadas de solo na produtividade de um latossolo vermel ho-escuro dos cerrados. R. bras. Ci. Solo, Campinas, 11:323-328, 1987.
DREGNE, H.E. Desertification: man's abuse of theland. J . Soil Wat. Cons., Ankeny, 33:11-15, 1978.

EMPRESA BRASILEIRA DE PESQUISAS AGROPECUÁRIA. Manual de métodos de análises de solo. Rio deJ aneiro, Serviço Nacional de Levantamento e Conservação de Sol os, 1979. 247p.

FOTH, H.D. Fundamentals of soil science. 6.ed. New York, J ohn Wiley, 1978. 436p.

HUDSON, N.H. Soil conservation. I thaca, Cornell University Press, 1981. 324p.

HUDSON, B.D. Soil organic matter and available water capacity. J . Soil Wat. Cons., Ankeny, 49:189-194, 1994.

MARGOLIS, E.; SILVA, A.B. da \& REIS, O.V. Controle da erosão com diferentes práticas conservacionistas num solo litólico de Caruaru (PE). R. bras. Ci. Solo, Campinas, 9:161-164, 1985.

MINISTÉRIO DA AGRICULTURA. Divisão dePesquisa Pedológica. Levantamento exploratório e de reconhecimento de solos do Estado do Ceará. Recife, 1973. v.1, 310p. (Série Pedologia, 16)

RESCK,D.V.S.;FIGUEIREDO, M.S.;FERNANDES, B.; RESENDE, M. \& SILVA, T.C.A. da. Intensidade de perdas de nutrientes em um podzólico vermel ho-amarelo, utilizando-se simulador de chuva. R. bras. Ci. Solo, Campinas, 4:188-192, 1980.

ROSSO, A. A conservação do solo através de patamar. In: CONGRESSO BRASILEIRO DE CONSERVAÇÃO DO SOLO, 4., Campinas, 1982. Resumos. Campinas, Sociedade Brasileira de Ciência do Solo, 1982. p.10.

SHAXSON, T.F.; HUDSON, N.W.; SANDERS, D.W.; ROOSE, E. \& MOLDENHAUER, W.C. Land husbandry: a framework for soil and water conservation. Ankeny, Soil and Water Conservation Society/World Association of Soil and Water Conservation, 1989. 64p.

SI LVA, J .E. da; LEMAINSKY, J \& RESCK, D.V.S. Perdas de matéria orgânica e suas relações com a capacidade de troca catiônica em solos da região do cerrado do oeste baiano. R. bras. Ci. Solo, Campinas, 18:541-547, 1994.

SI LVA,J .R.C. Erodibilidade dos sol os do Ceará: distribuição espacial e avaliação de métodos para sua determinação (1a. aproximação). Fortaleza, UFC, 1994. 60p. (Tese de Professor Titular).

SILVA, J .R.C. \& PAIVA, J .B. Retenção de sedimentos por cordões de pedra em contorno em uma encosta de solo litólico. R. bras. Ci. Solo, Campinas, 9:77-80, 1985.

SILVA, F.J . da \& SILVA, J.R.C. Produtividade de um solo litólico associada ao controle da erosão por cordões de pedra em contorno. R. bras. Ci Solo, Viçosa, 21:435-440, 1997.

SPAROVEK, G.; van LIER, Q.J .; ALOISI, R.R. \& VIDALTORRADO, P. Previsão do rendimento de uma cultura em solos de Piracicaba em função da erosão. R. bras. Ci. Solo, Campinas, 17:465-470, 1993.

SPAROVEK, G.; TERAMOTO, E.R.; TORETA, D.M.; ROCHELE, T.C.P. \& SHAYER, E.P.M. Erosão simulada e a produtividade da cultura do milho. R. bras. Ci. Solo, Campinas, 15:363-368, 1991. 